\title{
Network Embeddedness and Firm Innovation: An Empirical Research on Strategic Emerging Industries in China
}

\author{
Zheng Xiangjie $^{1}$ \\ ${ }^{1}$ College of Economic Management, Shangqiu Normal University, Shangqiu, P. R.C \\ Correspondence: Zheng Xiangjie, College of Economic Management, Shangqiu Normal University, NO.55, Ping \\ Yuan Middle Road, Shangqiu City, Henan Province, China. E-mail: xiangjie5065@163.com
}

Received: February 20, 2017

Accepted: April 20, $2017 \quad$ Online Published: April 27, 2017

doi:10.5539/ijbm.v12n5p209

URL: https://doi.org/10.5539/ijbm.v12n5p209

\begin{abstract}
The impact of strategic emerging industries alliance innovation network on firm innovation capability has been paid great attention by firms and academia. Supported by the social network analysis theory and method, we take the listed companies network embedded in the strategic emerging industries as an example, and use negative binomial regression to study the impact of network embeddedness on firm innovation capability. The empirical results show the firms embedded in alliance networks with better betweenness centrality will have greater innovative output in one or two years later; the liner relationship between the whole network density and the innovation ability is not obvious, but has a significant inverted $U$ type effect, in other words, the firms embedded in alliance network with moderately dense connection will have greater innovative output. These conclusions will provide new scientific basis for firms to develop alliance activities and for relevant government departments to make alliance policies.
\end{abstract}

Keywords: Social network analysis, firm embeddedness, strategic emerging industries, high-technology

\section{Introduction}

In recent years, strategic emerging industries has become an important force to achieve growth in downward pressure on the economy in China, the extensive alliance activities among firms have become an effective way for firms to improve their technological innovation capability and enhance their core competitiveness. Therefore, we are based on the theory of social network analysis, used the listed firms network embedded in the strategic emerging industry alliance innovation as an example, analyzed the relationship between network embeddedness and innovation capability. The reason for choosing the listed companies as the object of analysis is to eliminate the influence of the heterogeneity of capital scale on the firm innovation capability. On the one hand our conclusions provide a theoretical support for the listed companies in the strategic emerging industries to embed what kind of network and how to embed the network to obtain more innovative output, on the other hand our conclusions also provide a theoretical basis for the relevant government departments to develop strategic emerging industry alliance policy in order to promote the development of the industry better.

\section{Network Embeddedness and Firm Innovation}

Strategic emerging industries have become the core industry to seize the commanding heights of economic and technological development, its development mechanism has been attached great importance by many scholars and government departments(Lv Zheng, 2012). With the increasing fierce competition in the market and the complexity of technological innovation, innovation network of firms based alliance has become an important way for strategic emerging industry in innovation (Zheng Zhun, Yu Yajun, \& Wang Guoshun, 2012). The links between the firms are more and more closely, and also the boundaries are more and more blurred. The innovation of individual firm is gradually changing into group innovation, and the role play of firms in the group has been paid more and more attention to the influence of their innovation ability. Since the economic sociologist has put forward the idea that individual behavior is embedded in social network (Granovetter, 1984), scholars have conducted extensive research on the network embeddedness of individual behavior based on the perspective of social network, formed such as the structural hole theory, social capital theory, weak ties theory and so on. With the development of computer technology and the development of software design, the complex network of social relations based on graph theory is gradually coming into people's view. Therein, alliance network as an important organization network in social network, the impact of economic behavior of firms 
embedded and the choice to innovation output have become an important field in complex network.

In this research, more researchers in China are relatively more concentrated in the cluster network(Huang Xiao, Hu Hanhui, Yu Binbin, 2015; Zhou Zhong, Chen Zhigao, 2015; Lv Yibo, Cheng Lu, Su Jingqin,2015) than the alliance network. Scholars outside China used alliance database of SDC Platinum, MERIT-CATI and so on, launched the research based on negative binomial regression Model, Time lag model and other international common methods and found the small world network and scale-free network(Verspagen, Duysters, 2004). However, the domestic scholars are more prefer analog stimulation, theoretical explanation or case study (Wang Bin, 2016; Zhang Hongjuan, Tan Jinsong,2014; Song Zhihong, Li Changhong, Li Dongmei, 2013). Even some Chinese scholars did some empirical research (Peng Wei, Fu Zhengping, 2015; Zeng Saixing, Xie Xuemei, 2010; Chen Zifeng, Guan Jiancheng, 2009), their data were obtained through patent network, questionnaire and interviews, and this may involve the informal cooperation between firms except the formal alliance. Meanwhile, more studies involve only the overall network but rare to study the influence of individual network embeddedness and the integration of the overall network and the individual.

In social network analysis, the focus of embeddedness theory is to explore the

relationship between the embeddedness and individual innovation behavior and

innovation performance, while the scholars are considering the overall function of the social network, the network position and the overall network density are the key factors affecting the innovation and the development of embedded network (Qian Xihong, Yang Yongfu, Xu Wanli, 2010; ZhaoYan, Liu Zhongshi, 2012). Therefore, the impact of the network position embedded in the overall network and the network density of the strategic emerging industries on the innovation performance are the research content.

\subsection{Network Position and Firm Innovation}

Network position represents the rights of node, and it can be well explained by Resource Dependence Theory. In the social network, if a node plays an important role as an intermediary, it occupies many more resources, thus it controls the convenience of information transmission channels and seek benefits (Powell, Koput, Smith-Doerr, 1996; Koka, Prescott, 2002). In order to measure the importance of network node location, economic sociologist Freeman put forward the concept of betweenness centrality (Freeman, 1979), he believed that the betweenness centrality of the node linked by many more paths is also high, it is able to achieve a competitive advantage through the control and distortion of information transmission. For the inter-firm alliance innovation network, if a firm is connected with more firms, and it is in the path of connectivity, then it has more rights and control the flow of innovation resources, and also has the opportunity to get more information and through the comparison of various sources of information to get more valuable knowledge of innovation (Burt, 1992; Devi, 2001; Hansen, 2002). Therefore, firms in the network intermediary center have more opportunities to acquire more heterogeneous knowledge resources, and have more advantage in innovation. Hence, this study implies the first hypothesis:

H1: Firms that are embedded in alliance networks with better network position (higher betweenness centrality) will have more innovation output.

\subsection{Network Density and Firm Innovation}

Network density refers to the overall level of link between nodes, the more relationship numbers and the greater network density. The high density of the network provide variety of information opportunities to the node firms, at the same time, it also shortens the path of information and resources transfer, that is the information and resources in the network can quickly flow(Coleman, 1988; Valente, 1996). Meanwhile, with the increase of network density, it is easier for each other to develop the relationship for mutual trust, to carry out deep cooperation and communication, and improve the transfer of tacit knowledge which plays a key role in innovation (Inkpen, Tsang, 2005; Julia, Lin et al., 2009; Burt, 1998; Takahashi, 2000). However, with the further increase of the relationship among the firms in the network, the sharing of information and knowledge between firms becomes redundant, that is to say, the same knowledge resources will reach the same node firm through various paths. In addition, more network relationships may result in establishing common conventions and standards among firms (Uzzi and Spiro. 2005). These are likely to inhibit the creativity of firms. Therefore, there is a moderate network density in the alliance innovation network, which can make the embedded firms achieve the best innovation efficiency. So we come to our second hypothesis:

H2: Network density has a significant inverted U type impact on the innovation capability of embedded firms, that is to say, the firms are able to get a higher innovation output by embedding the network with moderate network density. 


\section{Data, Variables and Models}

\subsection{Data}

There are three main types of data used in the study. The first is patent data, through China Intellectual Property Net (http://www.cnipr.com) to collect sample firms patent data (the invention patents during 1995-2011); the second is the inter-firm alliance data, mainly from Thomson Corp.'s SDC Platinum database, it has been used in much empirical research about inter-firm alliance (Anand and Khanna, 2000; Sampson, 2004; Schilling and Phelps, 2007), then use the Chinese inter-firm alliance database to verify, supplement and consummate, on this basis, we use the classification standards of China's strategic emerging industries to build China's strategic emerging industry alliance data; the third is to reflect the characteristics of listed firms own data, such as geographical location, firm size, R\&D investment, etc, mainly through the disclosure of data from official website of the firms.

The relationship of inter-firm alliance are based on the alliance database of China's strategic emerging industry, assume that the duration of each alliance is 3 years, and base on three-year windows, through designing an undirected two element adjacency matrix algorithm to obtain the adjacency matrix of the alliance network automatically, and forme 7 time windows of alliance network (2000-2002、2001-2003、2002-2004、..

2006-2008), then apply UCINet, Eclipse and other software to calculate the network structure indications in each time window. From 7 time windows of the alliance innovation network we elected 420 listed firms (Observation of sample size). As table 1, it shows the number of samples for 7 time windows, figure 1 shows the structure of the alliance network of 83 observation samples embedded in China's strategic emerging industries of the time window in 2001-2003

Table 1. Number of firms in each time window (a total of 420)

\begin{tabular}{llllllll}
\hline $\begin{array}{l}\text { Time } \\
\text { window }\end{array}$ & $2000-2002$ & $2001-2003$ & 2002-2004 & 2003-2005 & 2004-2006 & 2005- 2007 & 2006- 2008 \\
\hline the number of firms & 79 & 83 & 67 & 34 & 37 & 52 & 68 \\
\hline
\end{tabular}

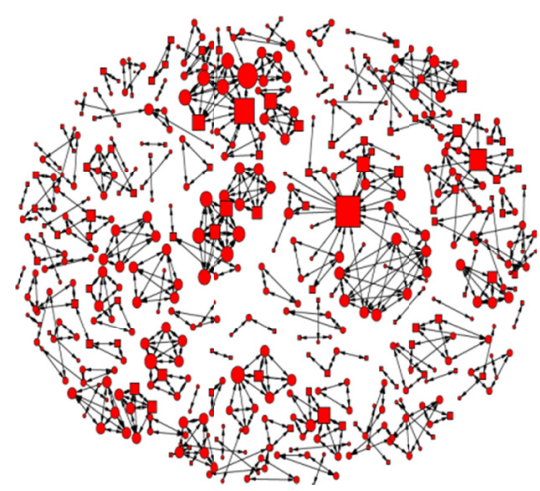

Figure 1. Inter-firm alliance network of the strategic emerging industries (2001-2003)

Note: the square represents listed firms, and the dot represents non listed firms; the size of the node represents the intensity of node firms in the center.

\subsection{Variables Specification}

\section{Dependent variable: number of patents (Patents ${ }_{i t}$ )}

In strategic emerging industries, most firms are high-tech firms, many of them mainly through the patent application to protect their own innovation. Therefore, the number of patents is an important indicator to embody firm innovation capability. Hence, the number of patents applied by the alliance firms in the past years and finally approved as the dependent variable.

2. Independent variables

(1) betweenness centrality $(B C)$

Calculating formula: 


$$
B C_{i}=\sum_{j<k} \frac{g_{j k}(i)}{g_{j k}}
$$

Where $g_{j k}$ is the shortest distance between $j$ and $k$. The term $g_{j k}(i)$ is the shortest distance between $j$ and $k$ through the distance of node $i$.

(2) network density(Density)

Calculating formula:

$$
\text { density }=\frac{2 l}{n(n-1)}
$$

where $l$ is the number of relationships in the alliance innovation network, $n$ is the number of nodes in the network. This variable ranges from 0 to 1 , with larger value indicating higher density.

\section{Control variables}

In order to control the firm own characteristics and the degree of consistency of each node in the network, we use the geographical position of firms embedded in alliance network (Zone) 、 firm size (Log-assets) 、R\&D investment $(\log -r d)$ 、 knowledge innovation accumulation (presample5, Pre5) 、 knowledge innovation accumulation of alliance partners (partner presample5, P-pre5) as the control variables.

If a sample firm in the network located in the well economically developed regions (China's three leading Economic zones , Bohai Rim region, the Yangtze River Delta and the Pearl River delta) , Zone $=1$, conversely Zone $=0$; using the total assets to indicate the scale of a firm, take its logarithm (Log-assets) enter model to eliminate the deviation caused by the magnitude, similarly, the R\&D investment of a firm is also in the form of logarithm ( $L o g-r d)$; the accumulation of knowledge innovation will affect the subsequent innovation capability, therefore, we choose the number of the sum of patents obtained by a firm in 5 years prior entry into the models. At the same time, the alliance partner's knowledge innovation accumulation has the opportunity to be studied and absorbed by the firm embedded in network, then promotes it to gain more innovation output, so we choose the number of the sum of patents in the 5 years prior obtained by alliance partners with a direct alliance relationship(as path1) as alliance partner's knowledge innovation accumulation (partner presample5, P-pre5) to entry into the models.

\subsection{Model Specification}

Number of patents, the dependent variable is non negative count data, so we use Poisson regression to analyze our models. However, the variance of number of patents is significantly higher than the mean, characterized by excessive dispersion, it's difficult to satisfy the assumption that mean equal variance. Therefore, we choose the generalized poisson model that is negative binomial regression model (to allow for excessive dispersion of the dependent variable) for empirical analysis

The establishment of strategic alliance often needs run a certain time, especially the results of innovation that new technology or new products apply for patents may take a long time (1-2years). Therefore, to ensure the stability of the results, we consider the negative binomial regression models, which are lagging behind for a period of 1 or 2 years, the general form of our models is provided as follows:

$$
\begin{gathered}
\text { Patents } \left._{i t+0(1,2)}=E \text { (patents }_{i t+0(1,2)} / \text { Density }_{i t}, \text { BC }_{i t}, \text { Pre }_{i t}, \text { P-pre } 5_{i t}, \text { Zone }_{i t}, \text { Log-assets }_{i t}, \text { Log-rd }_{i t}\right) \\
=\exp \left(a_{0}+a_{1} B C_{i t}+a_{2} \text { Density }_{i t}+a_{3} \text { Density }_{i t}{ }^{2}+a_{4} \text { Pre }_{i t}+a_{5} \text { P-pre }_{i t}+a_{6} \text { Zone }_{i t}+a_{7} \text { Log-asset }_{i t}+a_{8} \text { Log-rd }_{i t}\right)
\end{gathered}
$$

Where Patents $s_{i t+0(1,2)}$ represents the conditional expected number of patents granted to firm $i$ in 0 , 1, and 2-year lags, and the variables are indexed across firm $i$ and year $t$.

\section{Results and Discussion}

Table 2 is the descriptive and statistical analysis of the variables.. The average number of patents is significantly less than the standard deviation, it approves that the use of negative binomial regression models is appropriate. The absolute value of the correlation coefficient of independent variable is less than 0.7 , so there is no multicollinearity between independent variable.

Table 3 is the result of negative binomial regression analysis of random effects. The reason we choose negative binomial regression model with random effects is because Hausman test rejected the fixed effects model at the 
level of $p<0.01$. We get the low $\mathrm{P}$ value of the likelihood-ratio test for the results of each model that is the Poisson distribution is rejected at the level of $0.1 \%$, showing that the negative binomial regression model is more appropriate. At the same time we get the P value of the LR chi2 statistic for the overall significance of the models is also very low $(p<0.001)$, so each model has a high level of significance.

Table 2. Summary and correlation statistics ( $\mathrm{obs}=420)$

\begin{tabular}{llllllllll}
\hline & Mean & S.D. & Zone & Log-assets & Log-rd & Pre5 & P-pre5 & BC & Density \\
\hline Zone & 0.59 & 0.49 & 1.00 & & & & & & \\
Log-assets & 9.78 & 0.76 & 0.20 & 1.00 & & & & & \\
Log-rd & 7.76 & 0.93 & 0.11 & 0.66 & 1.00 & & & \\
Pre5 & 148.3 & 471.8 & 0.08 & 0.43 & 0.42 & 1.00 & & \\
P-pre5 & 109.4 & 407.7 & 0.07 & 0.20 & 0.09 & 0.03 & 1.00 & & \\
BC & 2.22 & 14.1 & 0.10 & 0.28 & 0.19 & 0.11 & 0.09 & 1.00 & \\
Density $_{\text {Patents }_{i t+0}}$ & 0.08 & 0.13 & 0.08 & -0.15 & 0.04 & 0.04 & 0.09 & 0.07 & 1.00 \\
Patents $_{i t+1}$ & 109.2 & 383.1 & & & & & & & \\
Patents $_{i t+2}$ & 126.4 & 432.4 & & & & & & & \\
\hline
\end{tabular}

Table 3. Negative binomial regression models with random effects $(\mathrm{Obs}=420)$

\begin{tabular}{|c|c|c|c|c|c|c|c|c|c|}
\hline \multirow{2}{*}{ Variables } & \multicolumn{3}{|l|}{ Patents $_{i t+0}$} & \multicolumn{3}{|l|}{ Patents $_{i t+1}$} & \multicolumn{3}{|l|}{ Patents $_{i t+2}$} \\
\hline & 1 & 2 & 3 & 4 & 5 & 6 & 7 & 8 & 9 \\
\hline Constant & $-8.47 * * *$ & $-8.35 * * *$ & $-7.37 * * *$ & $-8.64 * * *$ & $-8.40 * * *$ & $-7.51 * * *$ & $-5.75^{* * *}$ & $-5.63 * * *$ & $-5.26 * * *$ \\
\hline Zone & 0.211 & 0.191 & 0.221 & 0.195 & 0.192 & 0.271 & 0.091 & 0.087 & 0.156 \\
\hline Log-assets & 0.193 & 0.183 & 0.264 & 0.007 & 0.004 & -0.162 & -0.021 & -0.033 & -0.115 \\
\hline Log-rd & $0.88^{* * *}$ & $0.87 * * *$ & $0.93 * * *$ & $1.09 * * *$ & $1.12 * * *$ & $1.13^{* * *}$ & $0.81 * * *$ & $0.81 * * *$ & $0.84 * * *$ \\
\hline Pre5 & $0.001 * * *$ & $0.001 * * *$ & $0.001 * * *$ & $0.001 * * *$ & $0.001 * * *$ & $0.001 * * *$ & $0.001^{* *}$ & $0.001 * * *$ & $0.001 * * *$ \\
\hline P-pre 5 & $0.001 * * *$ & $0.001 * *$ & $0.001 * *$ & -0.001 & -0.001 & -0.001 & -0.001 & -0.001 & -0.001 \\
\hline$B C$ & & 0.003 & $0.002 *$ & & $0.003^{* *}$ & $0.004 * *$ & & $0.003^{* *}$ & $0.003^{* *}$ \\
\hline Density & & 0.10 & $3.06^{*}$ & & 0.45 & $3.63^{*}$ & & 0.05 & $3.69 *$ \\
\hline Density $^{2}$ & & & $-5.04 * * *$ & & & $-6.55^{* * *}$ & & & $-6.36 * * *$ \\
\hline Wald-chi' ${ }^{2}(n)$ & 182.23 & 189.56 & 201.06 & 130.72 & 144.58 & 167.05 & 76.45 & 83.20 & 94.63 \\
\hline Prob $>c h i^{2}$ & 0.000 & 0.000 & 0.000 & 0.000 & 0.000 & 0.000 & 0.000 & 0.000 & 0.000 \\
\hline loglikelihood & -1640.1 & -1639.1 & -1635.7 & -1705.58 & -1703.45 & -1698.45 & -1773.99 & -1772.59 & -1768.46 \\
\hline
\end{tabular}

Notes. Significant at $* p<0.1,{ }^{* *} \boldsymbol{p}<0.05, * * * p<0.01$ (two-tailed tests for all variables); standard errors are in parentheses.

Models 1, 4, 7 contain only the control variables, the impact of R\&D investment (Log-rd) and knowledge accumulation (Pre5) on firm innovation capability is significant. The accumulation of knowledge innovation alliance partners $\left(P\right.$-pre5) has significantly positive influences on patents it $+0_{0}$, and the significant impact disappears in 1- or 2-year lag. One explanation for this is that alliance firms have a great enthusiasm for acquiring partners' heterogeneity knowledge in the alliance current year, however, as time goes by, alliance firms get less effective heterogeneity knowledge from alliance partners. The firm location (Zone) has no significant influence on firm innovation capability, with the development of modern logistics and communication technology, location advantage for high-tech firms has become less important, in addition, Firm size (Log-assets) also has no significant influence on firm innovation capability, large scale firm may also not has higher innovation ability.

Betweenness centrality $(B C)$ has significantly positive impact on the firm innovation capability (Models5, 8), that is the firms embedded in alliance networks with better betweenness centrality will have greater innovative output in one or two years later, so $H 1$ is supported, but this kind of impact is not significant in Model 2, the impact $B C$ on firm innovation capability has obvious hysteresis, One important reason is that the firms occupied better location need cost some time to acquire and absorb the heterogeneity knowledge for their innovation. There is no obvious linear relationship between network density (Density) and firm innovation capability (Models2,5,8). However, the quadratic term coefficient of network density is obvious negative, but the monomial coefficient is positive in the models3, 6, 9, this shows that the network density (Density) has a significant 
inverted $U$ impact on the firm innovation ability, in other words, the firms embedded in alliance network with moderately dense connection will have greater innovative output. So $H 2$ is also supported.

In order to further explain the impact of network density on firm innovation capability, figure 2 are drawn according the model 3(similar figures can be drawn according the model 6 and 9 refer to the above). When only considering the network density (other factors are zero), Patents $s_{i t+0}=\exp \left(a_{2}\right.$ Density $_{i t}+a_{3}$ Density $\left._{i t}{ }^{2}\right)=\exp$ $\left(3.06\right.$ Density $_{i t}-5.04$ Density $\left._{i t}{ }^{2}\right)$, so $L N\left(\right.$ Patents $\left._{i t+0}\right)=3.06$ Density $_{i t}-5.04$ Density $_{i t}{ }^{2}$, thus we get the figure 2 .

As we can see from the figure, when the network density is less than 0.30357 , the innovation efficiency of the embedded firm is improved obviously with the increase of the network density; when the network density is equal to 0.30357 , then the embedded firm's innovation output reaches the maximum is Patentsit $+0=1.6$; when the density of the network is greater than 0.3 .357 , the efficiency of the innovation is gradually reduced.

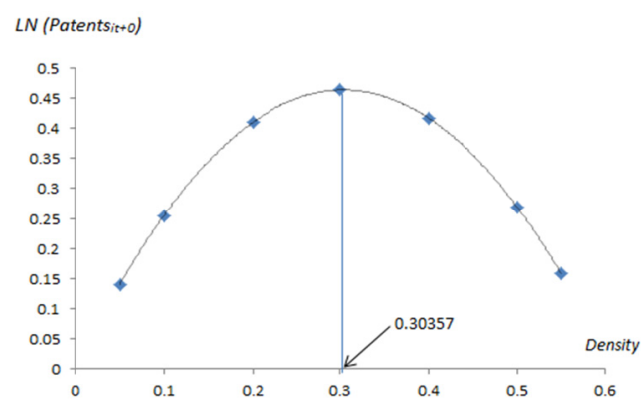

Figure 2. The impact of network density on firm innovation capability

\section{Conclusions and Implications}

Based on the hypothesis of the relationship between firm embeddedness and innovation, we take the listed firms network embedded in China's strategic emerging industries as an example to carry out empirical study. The main conclusions are as follows: the innovation advantages of firms embedded network center location will be reflected in one or two years later; the linear relationship between the network density and the firm innovation capability is not obvious, but has significant inverted $U$ type effect, that is to say, the firm can get more innovation output by embedding the network with moderate density.

Strategy alliance is an important way for firms to obtain innovation resources apart from the market transactions and operation internalization. The establishment of more alliance relationships is conducive to the sharing and circulation of innovation resources, providing the opportunity for firms to obtain innovation resources and the formation of innovation ideas. Different network positions have different opportunities to acquire knowledge resources, firms with better network position (higher centrality) occupy a large number of information sources. On the one hand, through comparing the various information sources firms are able to obtain useful knowledge for their own innovation; on the other hand, through occupying better location firms affect the entire network by controlling or distorting the transmission of information. Therefore, firms with better network position have strong innovation capability. Our conclusion also confirms this view.

The diversity of alliance network provides convenience for the access to innovative resources, but also increases the risk of core knowledge spillover. The more alliances, the higher the degree of network embeddedness (Inkpen, A.C, 2005), the higher the frequency of knowledge flows in the network. Meanwhile, firms have the opportunity to get more network resources, especially the tacit knowledge resources which pay a key role in the innovation of firms, are beneficial to the technological innovation and the upgrading of products. However, for high-tech firms, if there are the excessive connections among firms, they will worry the risk that the frequent exchange of information will leak their core knowledge. Therefore, many firms in the exchange of various alliance relations will be retained, especially for their own competitive relationship with the firms. At the same time, the excessive alliance relationships will make the redundant knowledge shared by the alliance to reach the same firm through many paths, the firm spent a lot of money and more efforts, but it has only acquired a lot of redundant knowledge. Hence, only when the firms embedded in a moderately dense connection can obtain higher innovation output.

Our conclusions have an important significance for firms to carry out the alliance 
activities and the relevant departments to formulate the alliance policies. While firms look for alliance partners, they should pay attention to the impact of network structure on their innovation, not only to ensure they are embedded in the better network position (the higher $B C$ ), but also to consider the various relationships of the global network and strive to embed in a moderately dense alliance network. In addition, firms should increase their knowledge accumulation, and improve the capability to absorb knowledge and the efficiency of acquiring and utilizing external knowledge resources. For the relevant department, on the one hand, they should build some platforms for cooperation and innovation for the firms, actively improve the innovation environment and encourage more firms to participate in the alliance through industrial policies and rewards and punishment mechanism, to realize the effective sharing of knowledge among firms and improve the innovation efficiency of the whole network. On the other hand, establish and improve laws and regulations, strengthen the legislative protection of intellectual property rights, so that firms are willing to share and exchange knowledge to protect the flow of knowledge resources in alliance innovation network.

\section{Acknowledgements}

This paper is funded by National Social Science Foundation of China: Clique Studies in Alliance Innovation Network of Strategic emerging industries in China (Project No. 15CGL007), the Foundation of Henan Province Soft Science of China (Project No. 162400410442).

\section{References}

Anand, B. N., \& Khanna, T. (2000). Do firms learn to create value? The case of alliances [J]. Strategic Management Journal, 21(3), 295-315. http://dx.doi.org/10.1002/(SICI)1097-0266(200003)21:3<295::AID-SMJ91>3.0.CO;2-O

Burt, R. S. (1994). Structural holes: The social structure of competition. The Economic Journal, 40(2). http://dx.doi.org/10.2307/2234645

Burt, R. S. (2000). The network structure of social capital. Research in Organizational Behavior, 22, 345-423. http://dx.doi.org/10.1016/S0191-3085(00)22009-1

Chen, Z. F., \& Gong, J. C. (2009). The impact of the small world of cooperative networks on innovation performance. Chinese Journal of Management Science, 17(3), 115-120.

Coleman, J S. (1988). Social capital in the creation of human capital. American Journal of Sociology, 94, 95-120. http://dx.doi.org/10.1016/B978-0-7506-7222-1.50005-2

Devi, R. G., \& Madhavan, R. (2001). Cooperative networks and competitive dynamics: A structural embeddedness perspective. Academy of Management Review, 26(3):431-445. http://dx.doi.org/10.2307/259186

Freeman, L. (1979). Centrality in social networks: Conceptual Clarifications. Social Networks, 1(3), 215-239. http://dx.doi.org/10.1016/0378-8733(78)90021-7

Granovetter, M. (1984). Economic action and social structure: The problem of embeddedness. American Journal of Sociology, 19(3), 481-510. http://dx.doi.org/10.17323/1726-3247-2002-3-44-58

Hansen, M. T. (2002). Knowledge networks: Explaining effective knowledge sharing in multiunit companies. Organization Science, 13(3), 232-250. http://dx.doi.org/10.1287/orsc.13.3.232.2771

Huang, X., Hu, H. H., \& Yu, B. B. (2015). Construction and evolution of new cluster network in industrial cluster transfer-theory and demonstration. Studies in Science of Science, 33(4), 539-548. http://dx.chinadoi.cn/10.3969/j.issn.1003-2053.2015.04.008

Inkpen, A. C., \& Tsang, E. W. K. (2005). Social Capital, Networks and Knowledge Transfer. Academy of Management Review, 30(1), 146-165. http://dx.doi.org/10.5465/AMR.2005.15281445

Julia, L. L. et al. (2009). Network Embeddedness and Technology Transfer Performance in R\&D Consortia in Taiwan. Technovation, 29(11), 763-774. http://dx.doi.org/10.1016/j.technovation.2009.05.001

Koka, B. R., \& Prescott, J. E. (2002). Strategic Alliances as Social Capital: A Multi-dimensional View. Strategic Management Journal, 23(9), 795-816. http://dx.doi.org/10.1002/smj.252

Lv, Y. B., Cheng, L., \& Su, J. Q. (2015). The impact of organizational inertia on the evolution of cluster network - simulation analysis based on multi topic modeling. Journal of management science in China, 18(6), 30-40. http://dx.chinadoi.cn/10.3969/j.issn.1007-9807.2015.06.003

Lv, Z. (2012).Research on the development of China's strategic emerging industries review. Economic 
Perspectives, (4), 160.

Peng, W., \& Fu, Z. P. (2015). Research on the relationship among alliance network, resource integration and high teach enterprise performance. Management science in China, 28(3), 26-37. http://dx.chinadoi.cn/10.3969/j.issn.1672-0334.2015.03.003

Powell, W. W., Koput, K. W., \& Smith-Doerr, L. (1996). Interorganizational collaboration and the locus of innovation: Networks of learning in biotechnology. Administrative Science Quarterly, 41(1), 116-145. http://dx.doi.org/10.2307/2393988

Qian, X. H., Yang, Y. F., \& Xu, W. L. (2010). Enterprise network position, absorptive capacity and innovation performance-an interaction model. Management World, (5), 118-129. http://d.wanfangdata.com.cn/Periodical/glsj201005013

Sampson, R. (2004). The cost of misaligned governance in R\&D alliances. The Journal of Law, Economics \& Organization, 20(2), 484-526. http://dx.doi.org/10.2139/ssrn.265994

Schilling, M. A., \& Phelps, C. C. (2007). Interfirm collaboration networks: the impact of large scale network structure on firm innovation. Management Science, 53(7), 1113-1126. http://dx.doi.org/10.1287/mnsc.1060.0624

Song, Z. H., Li, C. H., \& Li, D. M. (2013). The matching of technology alliance network and knowledge management motivation - a case study of SONY company based on 1995-2011. Studies in Science of Science, 31(1), 104-114. http://dx.chinadoi.cn/10.3969/j.issn.1003-2053.2013.01.014

Takahashi, N. (2000). The emergence of generalized exchange. American Journal of Sociology, 10(4), 1105-1134. http://dx.doi.org/10.1086/210400

Uzzi, B., \& Spiro, J. (2005). Collaboration and creativity: The small world problem. American Journal of Sociology, 111(2), 447-504. http://dx.doi.org/10.1086/432782

Verspagen, B., \& Duysters, G. (2004). The small worlds of strategic technology alliances. Technovation, 24(7), 563-571. http://dx.doi.org/10.1016/S0166-4972 (02)00123-2

Wang, B. (2016). Research on the mechanism of knowledge transfer efficiency in knowledge alliance. Scientific Research Management, 37(6), 159-167. http://d.wanfangdata.com.cn/Periodical/kygl201606019

Zeng, S., Xie, X., \& Tam, C. (2010). Relationship between cooperation networks and innovation performance of SMEs. Technovation, 30(3), 181-194. http://dx.doi.org/10.1016/j.technovation.2009.08.003

Zhang, H. J., \& Tan, J. S. (2014). Alliance network and enterprise innovation performance: Cross level analysis. Management World, (3), 163-169. Retrieved from http://d.wanfangdata.com.cn/Periodical/glsj201403014

Zhao, Y., \& Liu, Z. S. (2012). An empirical study on the impact of firm network position and resource location on innovation performance in alliance - based on the analysis of China's chemical industry alliance. $\begin{array}{llll}\text { Research and } & \text { Development }\end{array}$ http://dx.chinadoi.cn/10.3969/j.issn.1004-8308.2012.05.008

Zheng, Z., Yu, Y. J., \& Wang, G. S. (2012). Evolution mechanism of enterprise alliance network in strategic emerging industries - based on dissipative structure theory. Finance \& Economics in China, (6), 54-61. Retrieved from http://dx.chinadoi.cn/10.3969/j.issn.1000-8306.2012.06.007

Zhou, Z., \& Chen, Z. G. (2015). Simulation analysis of knowledge transfer behavior in industrial cluster network - enterprise knowledge rigid perspective. Journal of Management Science in China, 18(1), 41-49. Retrieved from http://d.wanfangdata.com.cn/Periodical/glkxxb201501005

\section{Copyrights}

Copyright for this article is retained by the author(s), with first publication rights granted to the journal.

This is an open-access article distributed under the terms and conditions of the Creative Commons Attribution license (http://creativecommons.org/licenses/by/4.0/). 